Claudio Paolucci*

\title{
The distinction between semantics and pragmatics: The point of view of semiotics
}

https://doi.org/10.1515/ip-2021-2014

Abstract: In this paper I will try to outline the reasons why, in order to understand the life and the nature of meaning, the semiotic tradition has always thought that it was better not to separate semantics and pragmatics. I will first reconstruct the history of this idea, grounded in Pragmatism and in Structural Linguistics. Later, I will deal with its first formulation in A Theory of Semiotics by Umberto Eco. In the second part of the paper, I will work on the idea by Ferdinand de Saussure that meanings are values, that is, indeterminate entities whose identity is determined only through reciprocal determination. I will claim that this idea is the importation in linguistics of Leibniz's principles of the differential calculus. In the final part of the paper, I will apply this idea to the distinction between semantics and pragmatics, claiming that meanings are better understood through a theory of modes of existence. If we understand the differential nature of meaning, we can see that meanings live only through the using of the expressions and these variations contribute to offer stability within the transformations, without creating a stable object defined by its properties and endowed with an independent existence split from the relationships that define it.

Keywords: differential semantics; pragmatics; Pragmatism; Saussure; semantics; Umberto Eco

\section{Semiotics on the distinction between semantics and pragmatics}

In this paper, I will try to outline Semiotics' position on the distinction between semantics and pragmatics. Since the Seventies of the last century, semiotics had a very original point of view on this topic: pragmatics is a part of semantics and it cannot be thought as separate from it. More, according to semiotics, semantics, in order to work properly, has to incorporate pragmatics as a constitutive part of its way to handle and describe meaning.

*Corresponding author: Claudio Paolucci, Department of Philosophy and Communication Studies, University of Bologna, Bologna, Italy, E-mail:c.paolucci@unibo.it 
In this paper, I will try to reconstruct the theoretical story that led semiotics to this claim and throw light on the reasons why semiotics traditionally claimed for such position, trying also to underline its strength.

In order to understand that, it has to be kept in mind that semiotics' semantics comes from a double source: on the one hand, it has his roots in American Pragmatism and its theory of meaning; on the other hand, it imports its own way to model meaning from structural linguistics (mainly Saussure and Hjelmslev). In the first part of the paper, I will deal with Pragmatism and the way it shapes the idea that pragmatics is a part of semantics in the semiotic work of Umberto Eco, mainly in his $A$ Theory of Semiotics. In the second part, I will deal with the structural linguistics' legacy for semiotics' semantics, trying to show a concrete model for a semiotics' semantics.

\section{Semantics, pragmatism and the pragmatic maxim}

At first glance, it seems paradoxical to ascribe pragmatism's legacy to the consideration of pragmatics as a part of semantics, seeing as the three-pronged division into syntax, semantics and pragmatics derives from Charles Morris' interpretation of certain ideas coming from Peirce. However, Umberto Eco (1975, 1984), who is the founder of semiotics' semantics grounded on the idea that pragmatics has to be considered as a part of semantics, thought that this idea by Morris was some kind of betrayal of the ideas of the pragmatists and, in particular, of the ideas that ground Pragmatism in the work of Charles Sanders Peirce. Indeed, a few of Peirce's ideas coming from the very foundation of Pragmatism were the ground of Eco's idea that pragmatics was part of semantics.

\footnotetext{
Pragmatics cannot be a discipline with its proper object as distinguished from those of semantics and syntactics. The three provinces of semiotics are dealing with the same disciplinary "object" [...] The object of pragmatics is that same process of semiosis that also syntactics and semantics focus on under different profiles. But a social and perhaps biological process such as semiosis can never be reduced to one, and only one, among its possible profiles. (Eco 1990: 205)
}

The non-separation of semantics and pragmatics is one of the most crucial ideas of Eco's semiotic legacy, one which has not been sufficiently considered and valued within a semantic landscape that uses Morris' tripartition as a starting point, if not a true cornerstone. As I have shown elsewhere (cf. Paolucci 2018), I am also convinced that Eco's idea is the direct result of Peirce's pragmatic maxim, which, in 
A Theory of Semiotics, Eco applied to the most modern problems of cognitive semantics of that time. ${ }^{1}$

Peirce's pragmatic maxim is in fact a theory of meaning. This is Charles Sanders Peirce's first formulation in his paper "How to Make our ideas clear":

Consider what effects, that might conceivably have practical bearings, we conceive the object of our conception to have. Then, our conception of these effects is the whole of our conception of the object. [...] There is no distinction of meaning so fine as to consist in anything but a possible difference of practice. (Peirce CP: 5.402).

In Seventies-era semantics, there was a tendency to enthusiastically distinguish between the meanings of a sign from its usage in language. Meaning was not about usage, and usage was actually a question of pragmatics, not semantics. This division tended to create numerous further distinctions, which Eco used to consider entirely artificial, such as that between dictionary and encyclopaedia and that between "knowledge of language" and "knowledge of the world" (see Eco 1975, 1984). We will start with the latter distinction: according to the semantic theories that Eco was opposed to, knowledge of the language (dictionary) would concern the fact that a bachelor is an "unmarried male adult", while a knowledge of the world (encyclopaedia) would concern the fact that the author of this essay is a bachelor. According to Katz (1972), who is the author of a semantic theory that embodies the polemic goal of $A$ Theory of Semiotics, encyclopaedic knowledge cannot be part of the meaning of a word since, as there are always new discoveries about the world (and thus new uses of words which have become the subject matter of common knowledge), this knowledge and these usages should be included in the semantic representation of a lexical item. For Katz, it was something that should not and must not be done, but, according to Eco (1975: 143-4), this was the very work of semantics itself. For this very purpose, in $A$ Theory of Semiotics, Eco (1975: 152-172) tried to propose a semiotic model founded on "coding contexts and circumstances". As we will now see, these codified contexts and circumstances represent those very "conceivable practical effects" that, according to Peirce, identified meaning.

Let me unpack this point a bit. Eco’s Reformulated Semantics Model (1975) inserts all of a sign's accepted meanings, along with the contextual and circumstantial selections that make it possible for us to use it within concrete linguistic practices (uses), into the semantic representation of that sign. "Contextual selections" make it possible to activate the correct meanings in function of the other, co-existing meanings of the sign in question. Meanwhile, "circumstantial selections" make it possible to activate the correct meanings in function of the events

1 On the relationship between Peirce and Eco, see Paolucci 2017a. 
and objects that co-exist in concrete linguistic practices. More generally, "the way to represent the meaning of a sign-vehicle $x$ is 'if $x$ then, according to the following circumstances and contexts, the following interpretants will be activated" (Eco 2017: 23). As such, the conceivable interpretative activity of the speaker, with the possible ways he could use language, becomes part of the semantic representation of a sign-vehicle, exactly like encyclopaedic knowledge, in its regularity, becomes an ineliminable component of semantics. It is a completely Eco-like way of interpreting the Peircean idea that, in order to determine the meaning of something, the conceivable practical effects must be determined.

Thus, according to Eco, the circumstantial and contextual selections have nothing to do with the empirical contexts and the empirical circumstances in which a word is used. For Eco, meaning is not related in any way to empirical uses, with "the practical effects of signs", but rather with the conceivable empirical uses, with the conceivable practical effects of signs, which Eco calls "the codes of contexts and circumstances”. It is clear how Eco is thinking here through Peirce's Pragmatism and not through its version by William James (Maddalena et al. 2015; Sini 1971). Meaning, in fact, does not consist in the identifiable practical effects of using a word. To the contrary, meaning consists in the conceivable practical effects, in other words (in Eco's semantic terminology), in the coding of contexts and circumstances, and thus in the concepts of the possible uses of a sign that are culturally and conventionally considered more probable.

The theory does not have to list and to structure all the possible occurrences of a given item but only those which are culturally and conventionally recognized as the more statistically probable. (Eco 1975: 110)

Eco does not dissolve meaning in its practical effects, just as he does not dissolve semantics in the empirical uses of speakers. Rather, he thinks that pragmatics, understood as a conceivable whole of the regularities of usage, is a constitutive component of meaning. For this reason, proper semantic representation must consider pragmatics to be a constitutive part of semantics itself. It is on this topic that Eco's pragmatist inspiration is not only evident but sows the seed of what in my opinion is one of the most important ideas of semiotic semantics.

Indeed, when Eco introduced his idea of the Encyclopaedia, namely "the ensemble of all registered interpretations, conceivable in objective terms as the library of all libraries, where a library is also an archive of all the non-verbal information that has somehow been recorded, from rock paintings to film libraries" (Eco 1984: 109, my translation), he was ready to tackle the distinction between semantics and pragmatics even more, paving the way to the revolution of cognitive semantics. Indeed, if the meaning of the word is encyclopaedic, the 
complexity of word meanings cannot be represented by any kind of closed model but must be seen as connected to a very broad and open repertoire of all kinds of knowledge, including contextual information.

One of the central tenets of cognitive semantics is that the meaning of words is encyclopedic: everything you know about the concept is a part of its meaning ... Thus, that aspect of "pragmatics" which involves the employment of "world knowledge" or "common-sense knowledge," and even contextual knowledge (since the speech act context is part of our world knowledge, albeit a very specific piece of knowledge), becomes part of semantics. (Croft 1993: 336-337)

This core idea coming from cognitive semantics was the cornerstone of semiotic semantics, that Eco already formulated in 1975, inspired by Pragmatism and tackling both compositional semantics and one of the traditions of the philosophy of language, the one grounded on truth-conditional semantics. On the one hand, as far as truth-conditional semantics is concerned, there is a nice memory that Umberto Eco used to tell his students in his classes of Semiotics at the University of Bologna during the mid-Nineties. Eco recalled that, at the beginning of the Seventies, he met with Roland Barthes in Paris (Eco and Barthes were friends) and they talked about semantics, telling each other in front of a drink that the main aim for a semiotics semantics was to kill the referent: "il faut tuer le référent". Indeed, if semantics is thought of in a truth-conditional way, attempting to define the meaning of a proposition by explaining what would happen in the world when the sentence is true (see Davidson 1967), all the knowledge cut out by truth-conditional theories would be a matter of pragmatics. However, as we will see in our next paragraph, semiotic semantics, inspired by Saussure's legacy, denied exactly this definition of meaning, that inevitably lead to a separation between semantics and pragmatics.

On the other hand, as far as compositional semantics is concerned, the insuperable limit of all the strictly compositional models of meaning is obviously the issue of context.

The role of context in lexical semantic representations immediately brings into play the pragmatic component of language and opens the perennial, never resolved, issue of the relationship between semantics and pragmatics. This opening to pragmatics, although an obligatory step, in fact poses more problems than it resolves given the elusive and essentially indefinable nature of context, which can range from the simple "linguistic surroundings" sometimes defined as a context, to the virtually infinite set of all extra-linguistic elements which arise in actual enunciation situations. Context thus appears to be a sort of real "black hole" for lexical semantics not only because it is difficult to delimit, but also because it affects in quite different ways the "inferential computations" that ought to lead us to the desired interpretation. (Violi 2015: 92) 
According to Violi, semantics seems to be trapped in a paradoxical situation: on the one hand, it seems natural to associate lexical items with stable meanings; on the other hand, whenever one tries to describe these meanings in a generalized and principled form there seems to be no viable way out. "All attempts in this direction have turned out to be unsuccessful, starting with the strict compositional models of structural semantics and up to the rather more flexible prototypical models that however cannot manage to cope adequately with the problem of context" (Violi 2015: 89). Since meaning is always to some extent underdetermined, semantic models seem always either too rich and constrictive, or too poor and simplistic.

In the second part of this paper, I will try to show a possible way to overcome all that, trying to build a semiotic model of meaning and of its indetermination grounded in Saussure's legacy, overcoming both compositional models of meaning and truth-conditional semantics, also erasing the distinction between semantics and pragmatics.

\section{Semiotics' differential semantics: a Saussurean model}

In his Writings on General Linguistics, it is very clear that Saussure thinks about semantics on the basis of the very same differential theory of value through which, in his Cours de linguistique générale, he was thinking about linguistics and semiotics:

[The] relationship of two phonemes correlated with different 'meanings' = still simply their reciprocal value. Here one can begin to see that meaning and value are the same. [...] We do not find any significant difference between the terms value, meaning, signification, function or use of a form, nor even with the notion or content of a form: these terms are synonymous. It must be accepted however that value expresses better than any other word the essence of this concept, which is also the essence of the language system. [...] The meaning of each particular form is the same as the difference between the forms. Meaning = difference in value. (Saussure 2002: 10, 12, 13)

Let us try to put this definition into practice, in the direction of a "differential semantics" based on the idea of value. If "meaning" coincide with "difference in value", differential semantics will define meaning by appealing to a series of semantic values that are reciprocally determined according to their use in language, or, to use one of Eco's theoretical objects (1984) introduced above, according to the encyclopedic section that is cut out in the ongoing practice, with its "circumstantial selections" and "contextual selections" that define its 
peculiarities. ${ }^{2}$ This reciprocal determination between differential values will give rise to certain interpretants, which allow us to define the effect of meaning at stake.

For example, in Semiotics and the Philosophy of Language, Eco (1984) showed how the nature of the Italian expression "dare una lezione" changed from "masterfully win" to "punishing somebody", in the transition from the order of sport to the order of education. In relation to sport, this unit of content is determined by other elements belonging to that area ("being defeated", "winning by stealing”, "deserving to win”, "losing just because a few points") and thus it gives birth to a certain type of Interpretants ("to masterfully win"). But, within another order, things change, so that the identity of "dare una lezione" is determined within another set of relationships ("teaching an academic course", "rewarding someone”, “controlling someone’s behavior”, "being tolerant” etc.). It thus gives birth to another type of Interpretant-sign ("punishing somebody”, indeed).

But, following Saussure, "dare una lezione" is nothing in itself: its identity is defined only by the other elements through which it is reciprocally determined on a given level, following a given use of language. Outside that level, within another universe of discourse in which that element establishes relations with other elements, things change. These are values and, according to Saussure's thought, the identity of a value is defined exclusively by other elements with which it is reciprocally determined. This is worth a deeper look. As I have shown elsewhere (Paolucci 2004, 2012), the Saussurean revolution - first in the sciences of language and later in the humanities - consisted in the introduction of the revolutionary principles of differential calculus in linguistics.

In the differential calculus, at the limit point of a primitive function, the elements in relation become relations between elements. These relations give rise to a new function, derivative but completely independent from the primitive one. Indeed, if the primitive function expresses the curve, the derivative function expresses the tangent $(t)$ that cuts the curve "in two points that coincide", as Leibniz says. At the limit point there is a change in the nature of the function. In the primitive function, $\Delta y$ and $\Delta x$ have a relationship with the $y$-axis and the $x$-axis (as shown in Figure 1). On the contrary, in the derivative function, $d y$ has no relation to $y$ and $d x$ has no relation to $x$. The identity of these elements is purely relational and differential, and it is realized by reciprocal determination: these elements are what the other elements are not. Therefore, at the limit point we move from what is determined $(\Delta y, \Delta x)$ to what is indeterminate $(d y, d x)$, just as in Alice in Wonderland we move from one side of the mirror to the other. The $d y$ and $d x$ are indeterminate in relation to the quantities $x$ and $y$ : they have neither individual identity nor any kind

2 Cf. L. de Saussure 2003 and infra. 


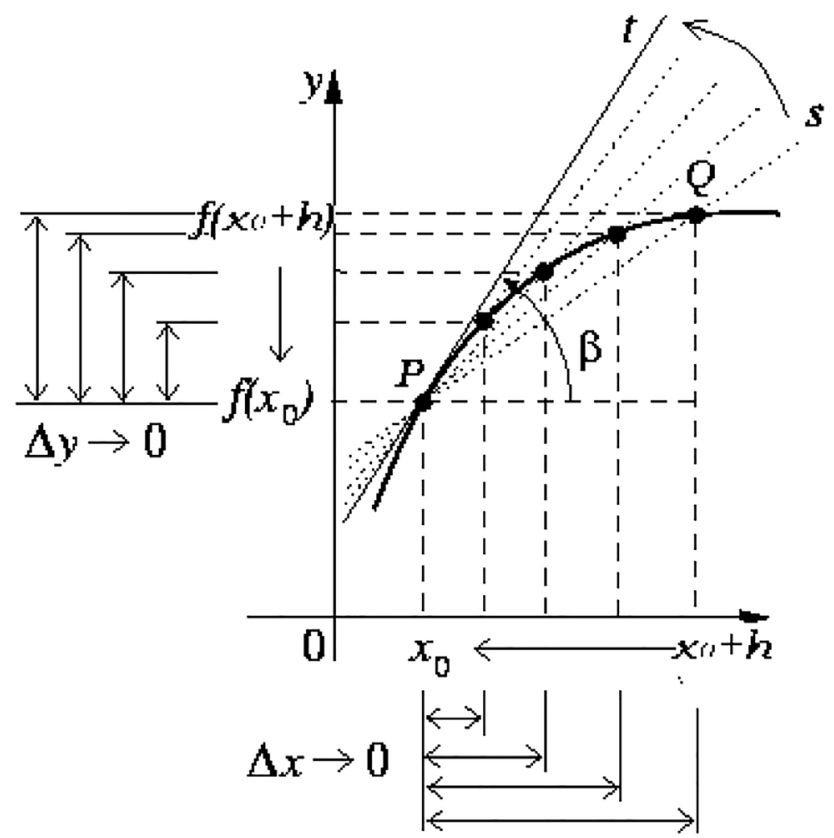

Figure 1: $\lim \Delta y / \Delta x=d y / d x$. $\Delta y \rightarrow 0$.

of independent existence. Nonetheless, they both can be determined by reciprocal determination $(d y / d x)$, and this relationship defines the values of the equation and the identity of the components of the function, which is determined through difference. This is why, in mathematics, these entities are called differentials. This passage from a series of elements with a given identity entertaining relations with each other to a set of relations that creates the identity of the elements is the great revolution of differential calculus, which Saussure will introduce in linguistics and in the Humanities.

Jakobson (1978: 46-52) already noticed the Saussurean obsession for the problem of the identity (cf. Basso Fossali 2014: 95). Indeed, according to Saussure, in Western thought there would have been "poor research on what identity is or on what the features of identity are when non-existent beings like words, a mythical character or a letter of the alphabet are concerned. These are only different forms of the SIGN, in the philosophical sense" (Saussure 1986: 191, 2003: 387).

Clearly, this is a very peculiar series of items: words, mythological characters and letters of the alphabet are all entities that belong to the semiological systems and, according to Saussure, they are "non-existent". Here we see the inadequacy of 
classical ontology, according to which only mythical characters, but certainly not words and letters, could be defined as "non-existent". As a matter of fact, Saussure is saying that all these entities have a relational identity that varies with the variation of the position of these entities inside a given system, and with the variation of the entities with which they have a relation. For instance, a phoneme $(d y)$ is nothing in relation to the material entities that embody it $(\Delta y, \Delta x)$, because its identity is defined only by the differential relations it has with the other phonemes $(d y, d x)$, through which it is reciprocally determined $(d y / d x)$. A phoneme is only what the other phonemes are not. The same applies to all linguistic entities, such as words, signs, mythological characters, letters of the alphabet and meanings. Each of these entities lives only through its variations (versions of the myth, the use of the words, the pronunciation of the phonemes and the way we write the letters). These variations contribute to offer stability within the transformations without creating a stable object defined by its properties and endowed with an independent existence. For this reason, "an observation of particular vocal facts which overlooks considerations on their identity does not provide us with any object", since "outside a relationship of identity whatsoever, linguistic facts do not exist” (Saussure 2002: 33, 200). The very same thing applies to meaning and drives to the overlapping of semantics and pragmatics: every meaning lives only through its variations, it lives only through the use of the words and these variations contribute to offer stability within the transformations, without creating a stable object defined by its properties and endowed with an independent existence apart from the relationships that define it.

For instance, the keystroke on my computer's keyboard, QWERTY, is an expression, but its meaning depends on the encyclopedic order taken into account. For example, it has no meaning on a linguistic level (QWERTY means nothing in English), it expresses the statement of the alphabetical order adopted by English notebook keyboards if "activated" in a handbook on typewriting, it constitutes the desired and regretted object of a romantic Sensucht when working in Paris on French AZERTY keyboards, it constitutes the example of the mechanism of differential semantics, if written in a paper about the relationship between semantics and pragmatics.

Unless I am mistaken, objects of study in other areas can be said to have their own existence, or failing this to encapsulate certain positive things or entities requiring different formulation. [...] The science of language appears to be in a different situation. [...] Now, it is fundamental to and inherent in the nature of language that from whichever side - whether appropriate or not - one tries to tackle language, there can never be found individual entities, that is entities (or quantities) that can be defined in themselves [...] and that possess an independent existence. Let us remember in fact that the object in linguistics does not exists to start with, it is not predetermined in its own right. (Saussure 2002: 8, 42) 
This is what happens with entities that are not individuals, like in the case of the entities of language: they are not determined, but they are determinable, and their determination always takes place through reciprocal determination. Thus, Saussure introduces the constitutive principle of Leibnizian differential calculus into linguistics: hence the "differential" nature of the units of language and semiosis. Hence the great revolution of Saussure: linguistic objects do not depend on conceptual schemas and on the perceptual apparatuses that would constitute them (Copernican Turn), nor they depend on their ontological properties (Ontological Turn). On the contrary, they depend on the inter-objectivity of entities that reciprocally determine themselves (Semiotic Turn). This is true especially for meanings.

\section{The modes of existence of meaning}

In spite of the identification, offered in the Cours de linguistique gènerale (Saussure 1959), between meaning and concept, it seems to me that the real "modernity of Saussurism" precisely consists in the equation "meaning=difference in value", that Saussure introduces in his Writings in General Linguistics. This idea differentiates a semio-linguistic semantics from any previous attempt to develop a theory of meaning. Indeed, in the entry "Word Meaning" of the Cambridge Encyclopedia of the Language Sciences, in order to introduce the "most important" contemporary approaches to meaning, Vyvyan Evans (2010) presents this idea as a "widely accepted" conception.

The conventional meaning associated with a word is often thought of, more technically, as a semantic representation, a semantic unit or a lexical concept. This is to say that, in modern linguistics, the meanings of words are thought to be conceptual entities, they are conceived as mental units, coupled with phonetically realizable forms, and stored in long-term memory.

The central aspect of a Saussurean approach to meaning, as the one we are proposing here, is by no means in conformity with "modern linguistics", since it consists in recognizing the peculiarity of the semantic level, setting it free it from any kind of reduction to the concept, both in its logical and in its cognitive sense: the objects of semiotic domains, like meanings, are not constituted by concepts or by the properties of the elements themselves. They are reciprocally determined through inter-objectivity. "Existing signs ... produce, by their simple presence and the accidental state of their DIFFERENCES at every moment of the language, and equal number not of concepts, but of values understood to be mutually differentiated“ (Saussure 2002: 60).

Following Saussure, it will be necessary to define the meaning of a signifier without referring to other orders of reality, such as concepts, referents and the 
different relations that can be identified between these elements (truth conditions, symbolization, categorization, pragmatic conditions of enunciation, etc.). It will be necessary to define the meaning of a signifier in relation to realities of the same order, in function of the differences with other meanings, or, better, with other semantic values. ${ }^{3}$ Hence the centrality of a differential approach to semantics and the construction of an immanent theory, which is beyond any possible reduction of meaning to the concept or to other orders of "reality".

For instance, if we take a case of antanaclasis like "cinema is cinema", the problem at stake is that of the difference between the two occurrences of the word "cinema", which is irreducible both to the concept of cinema and to its possible referents. Indeed, if the first occurrence actually concerns cinema, the semantic value of the second one is simply "something unique" and that has nothing to do with the semantic value of the first occurrence. It is a pure position within a given differential level, a value, so much so that the same semantic value can be taken, for example, by "apple" in the sentence "apple is apple", or by "platypus" in the sentence "platypus is platypus". On the contrary, according to truth-conditional semantics, the sentence "cinema is cinema" would be a tautology, while following cognitive semantics, the concept of cinema is that of "cinema", and if cinema appears first, as a subject, or later, as the object of the verb, it is a difference that does not actually make the difference, since there is nothing we can know about cinema that can help us understand and disambiguate the meaning of the second occurrence in sentences like this.

It is therefore necessary to stress that meaning is never exclusively constituted by the conditions of reference to objects, nor by the possible inferences between concepts, but also and mainly by the differences between immanent elements that are reciprocally determined on a local basis. For this reason, referential semantics and inferential semantics must first be supported by a semantics that is constitutively differential. The inter-objectivity of the reciprocal determination between values $(d y / d x)$ leads us to define meaning as a function of the differential relations between elements belonging to heterogeneous systems. Beyond the concepts and the inferences that can be drawn from them, beyond the objects and their conditions of truth, Saussure discovers a third semio-linguistic realm, whose entities are radically irreducible to classical ontology. In fact, the value of a linguistic object is essentially something relational and privative, which, as such, does not have a "quiddity", does not have an essence, does not have an Aristotelian or scholastic quod quid est. Indeed, "quiddity" defines the thing through its being what it cannot but be. On the contrary, a semiotic value, in the Saussurean sense, defines a term through its being what the other terms are not, which is quite another thing

3 Cf. Rastier 1991. 
(cf. Rastier 2001: 239). Hence the Saussurean idea that the elements of language (values) are non-individual entities, which are not endowed with an independent existence, which are not determined in themselves and that cannot be defined by appealing to their properties (cf. Saussure 2002: 14-5 and 71).

There is a beautiful idea by Quine (1953), according to which meanings are not types of entities, since they do not have a defined identity that would allow us to distinguish when two statements have the same meaning. For Quine, meanings do not exhibit conditions of determined identity, which would make them "respectable entities". ${ }^{4}$ But it is exactly this indeterminacy, which then extends into the determinability of elements that are reciprocally determined, that constitutes the peculiarity of the semantic level, as it constitutes the peculiarity of the differential calculus. Indeed, taken as such, the infinitesimal differentials are completely indeterminate $(d v, d t)$, but they are perfectly determinable in relation to each other $(d y / d x)$, and their determinability consists in a reciprocal determination (values of $d y$ and $d x$ ). Semantics works in the very same way. Meaning is always something essentially indeterminate, since any expression can always spread across a thousand encyclopedic levels (for example: "QWERTY”). But this indeterminacy does not prevent meaning from extending into a determinability of its elements, according to the genres, norms and practices in which it is instantiated (the literary genre of typewriting handbooks, the system of linguistic values, the practice of writing on a French computer, etc.). Therefore, within these micro-systems, semantic processes lead to an effective reciprocal determination of differential values (e.g. QWERTY VS AZERTY and this VS the mental habit of searching for letters where they are not placed): a whole micro-system of semantic values.

In this way, it is possible to reassess the semiotic theory of the modes of existence originally elaborated by Greimas and Fontanille (1991) and combining it, at a semantic level, with the theory of the Saussurean value in its differential specificity. In semantic analysis, i) the determination of meaning always starts from an indeterminate state which is potentialized, ii) on the basis of the cut of the encyclopedia through interpretative habits, this indeterminate becomes determinable (virtualized state); iii) the reciprocal determination of the semantic elements defines an actualized state that iv) the interpretation realizes by specifying it through interpretants, thus accounting for the effect of sense (realized state). Therefore, it seems to me that philosophical semantics, from Frege to Russell, from Tarski to Davidson, from Carnap to Quine and Dummett, has always been too inspired by mathematical logic and by its conditions of truth, while it should have been inspired also by mathematical analysis, and by its "distribution" of relations and points corresponding to the values of these relations, which is a quite different

4 "Without identity, there is no entity" (Santambrogio 1991: 199). 
thing. In my opinion, the differential nature of meaning is the most important element that is absent from the tradition of philosophy of language and is the semio-linguistic answer to Quine's observations on the status of meaning.

\section{Conclusions}

Since meaning refers to the differential relations that determine the identity of every single element of the content plane, lexical usage does not seem to correspond to a linear and predictable logic of tokens that repeat, transform and module the respective type (or prototype). When we repeat lexical forms in a given context and for specific relational purposes, we inevitably alter and vary the meaning of these forms. Since meanings are endowed with a capacity for activating their semantic potential and transform their modes of existence, they are not specified by contexts, but they function as activators of contexts where a unit of content is determined by other units through reciprocal determination (inter-objectivity).

Instead of being split between the study of the relation between linguistic expressions and their meanings (Semantics) and the study of the way context can influence our understanding of linguistic utterances (Pragmatics), meanings are better understood through a theory of modes of existence brought forth by different enunciating instances. Inside a sentence there are different voices “assembled": a norm can be potentialized, a usage can be virtualized, other sentences can be actualized (quoted) or virtualized (hidden) and the meaning of the sentence is the result of the copresence of different instances of enunciation (Fontanille and Zilberberg 1998; Paolucci 2017b, 2020). If we understand the differential nature of meaning, we see that meanings live only through the use of the expressions and these variations contribute to offer stability within the transformations without creating a stable object defined by its properties and endowed with an independent existence split from the relationships that define it.

Therefore, the semiotic tradition has always thought that it was better not to separate semantics and pragmatics in order to understand the life and the nature of an entity which, as Saussure has taught us, is not determined on its own.

\section{References}

Basso Fossali, Pierluigi. 2014. Il fatto linguistico, l'identità culturale dei segni, l'incidenza paradigmatica: tensioni interne al modello saussuriano. In P. Fabbri \& T. Migliore (eds.), Saussure e i suoi segni. Roma: Aracne. 
Croft, William. 1993. The role of domains in the interpretation of metaphor and metonymies. Cognitive Linguistics 4(4). 335-370.

Davidson, Donald. 1967. Truth and meaning. Synthese 17(1): 304-323.

Eco, Umberto. 1975. Trattato di Semiotica Generale. Milano: Bompiani. (English translation, Bloomington: Indiana University Press, 1975).

Eco, Umberto. 1984. Semiotica e filosofia del linguaggio. Torino: Einaudi. (English translation, Bloomington: Indiana University Press, 1984).

Eco, Umberto. 1990. I limiti dell'interpretazione. Milano: Bompiani. (English translation, Bloomington: Indiana University Press, 1990).

Eco, Umberto. 2017. Intellectual autobiography. In S. Beardsworth \& R. Auxier (eds.), The philosophy of Umberto Eco. Chicago: Open Court.

Evans, Vyv. 2010. Word meaning. In Patrick Hogan (ed.), Cambridge encyclopedia of the language sciences. Cambridge: Cambridge University Press.

Fontanille, Jacques \& Claude Zilberberg. 1998. Tension et signification. Liège: Mardaga.

Greimas, Algirdas Julien \& Jacques Fontanille. 1991. Sémiotique des passions. Paris: Éditions Du Seuil.

Jakobson, Roman. 1978. Lo sviluppo della semiotica e altri saggi. Milano: Bompiani.

Katz, Jerrold. 1972. Semantic theory. New York: Harper \& Row.

Maddalena, Giovanni, Rosa Maria Calcaterra \& Giancarlo Marchetti (eds.). 2015. Il pragmatismo. Dalle origini agli sviluppi contemporanei. Roma: Carocci.

Paolucci, Claudio. 2004. Piegature della continuità: semiotica interpretativa e semiotica generativa. Versus 97. 111-149.

Paolucci, Claudio. 2012. Identité, Sémantique, Valeur. L'actualité de Saussure pour la sémiotique contemporaine. Cahiers Ferdinand de Saussure 65. 81-102.

Paolucci, Claudio. 2017a. Eco, peirce, and the anxiety of influence: The most Kantian of thinkers. In Sara G. Beardsworth \& Randall E. Auxier (eds.), The philosophy of Umberto Eco, 251-276. Chicago: The Library of Living Philosophers, Open Court.

Paolucci, Claudio. 2017b. Prothèses de la subjectivité. L'appareil formel de l'énonciation dans l'audiovisuel. In Maria Giulia Dondero, Anne Beyaert-Geslin \& Audrey Moutat (eds.), Les plis du visuel. Réflexivité et énonciation dans l'image, 53-68. Limoges: Lambert-Lucas.

Paolucci, Claudio 2018. Three pragmatist legacies in the thought of Umberto Eco. European Journal of Pragmatism and American Philosophy X(1).

Paolucci, Claudio. 2020. Persona. Soggettività nel linguaggio e semiotica dell'enunciazione. Milano: Bompiani.

Peirce, Charles Sanders. CP. Collected papers. Cambridge: Harvard University Press.

Quine, Willard Van Orman. 1953. On what there is. In Willard Van Quine (eds.), From a logical point of view, 1-19. Cambridge, Massachusetts: Harvard University Press.

Rastier, François. 1991. Sémantique et recherches cognitives. Paris: P.U.F.

Rastier, François. 2001. Du signe aux plans du langage. Cahiers Ferdinand de Saussure 54. 177-200.

Santambrogio, Marco (ed.). 1991. Introduzione alla filosofia analitica del linguaggio. Roma-Bari: Laterza.

Saussure, Ferdinand De. 1959. Cours de linguistique générale. Lausanne-Paris: Payot. (English translation, New York: Philosophical Library, 1959).

Saussure, Ferdinand De. 1986. Le leggende germaniche. In Anna Marinetti \& Marcello Meli (eds.). Padova: Zielo, Este. 
Saussure, Ferdinand De. 2002. Écrits de linguistique générale. Paris: Gallimard. (Italian translation, Roma-Bari: Laterza, 2005. English translation, Oxford: Oxford University Press, 2008).

Saussure, Louis De. 2003. Valeur et signification ad hoc. Cahiers Ferdinand de Saussure 56. 289-310.

Sini, Carlo. 1971. Il pragmatismo americano. Roma-Bari: Laterza.

Violi, Patrizia. 2015. Global and local: Encyclopedic meaning revisited. Semiotica 206. https://doi. org/10.1515/sem-2015-0023.

\section{Bionote}

\section{Claudio Paolucci}

Department of Philosophy and Communication Studies, University of Bologna, Bologna, Italy c.paolucci@unibo.it

Claudio Paolucci is Professor of Semiotics and Philosophy of Language at the Department of Philosophy and Communication Studies of the University of Bologna (Italy). He is the scientific coordinator of the International Centre for Humanities "Umberto Eco" and the coordinator of the $\mathrm{PhD}$ programme in Philosophy, Science, Cognition and Semiotics of the University of Bologna. He is currently the Principal Investigator of two European Projects on embodied interactions (NeMo) and fake news (Fakespotting). His research is focused on Semiotics, Semantics, Cognitive Sciences, Theory of Enunciation and Subjectivity, Enculturation and Social cognition (with a special focus on Autism Spectrum Disorders). He has published more than 100 papers and five books. His last book is Cognitive Semiotics. Integrating Signs, Minds, Meaning and Cognition (Springer, 2021). He is the director of the International Centre for Enactivism and Cognitive Semiotics. 